Portland State University

PDXScholar

6-1-1976

\title{
A Development of Natural Forms in Multiple Glass Shapes
}

Anthony Parker

Portland State University

Follow this and additional works at: https://pdxscholar.library.pdx.edu/open_access_etds

Part of the Fine Arts Commons

Let us know how access to this document benefits you.

Recommended Citation

Parker, Anthony, "A Development of Natural Forms in Multiple Glass Shapes" (1976). Dissertations and Theses. Paper 2421.

https://doi.org/10.15760/etd.2418

This Thesis is brought to you for free and open access. It has been accepted for inclusion in Dissertations and Theses by an authorized administrator of PDXScholar. Please contact us if we can make this document more accessible: pdxscholar@pdx.edu. 
AN ABSTRACT OF THE THESIS OF Anthony Parker for the Master of Fine Arts in Ceramics presented June 1, 1976.

Title: A Development of Natural Forms in Multiple Glass Shapes

APPROVED BY MEMBERS OF THESIS COMMITTEE:

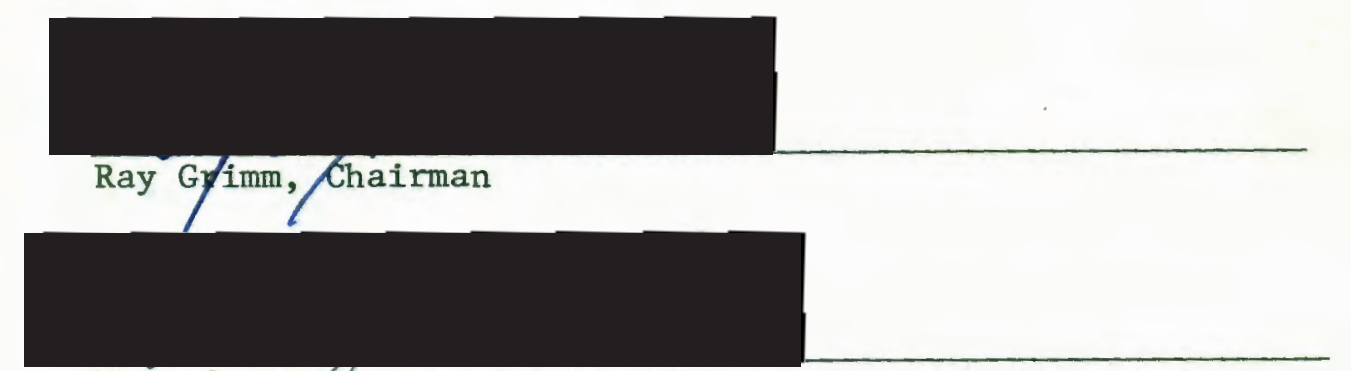

Mary Constäns
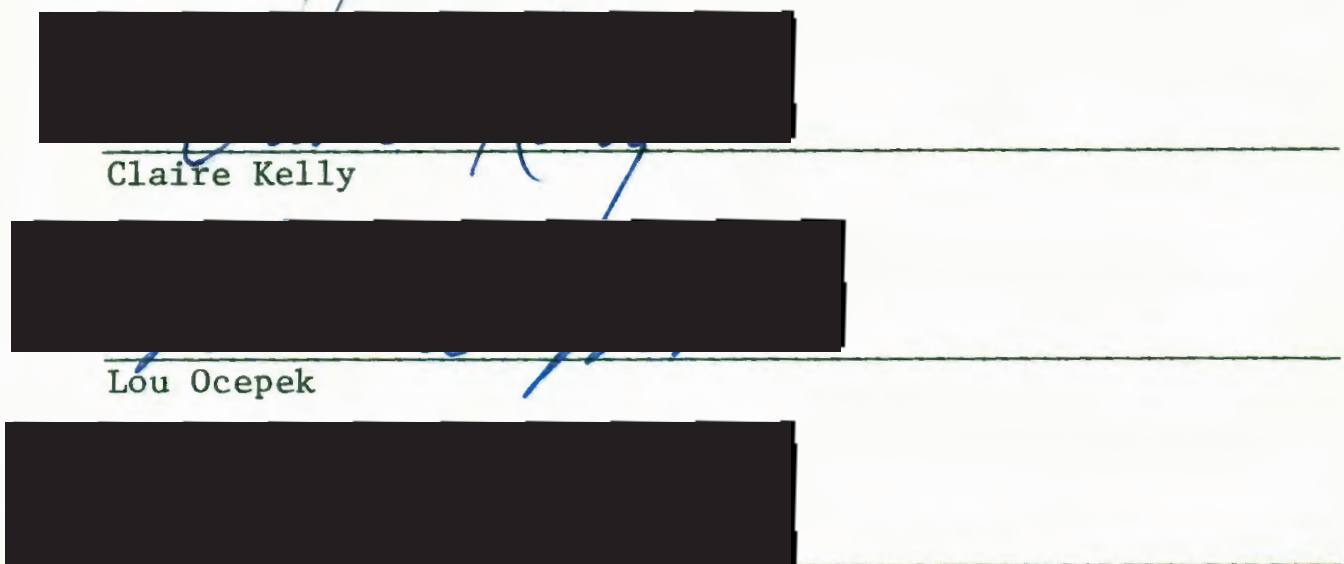

Dan Schwoerer

This thesis is the description of an attempt to overcome the restrictions of glass sculpture by expanding and developing techniques for the creation of organic glass forms which are consolidations of individual glass shapes. 
A DEVELOPMENT OF NATURAL FORMS IN

MULTIPLE GLASS SHAPES

BY

ANTHONY PARKER

A thesis submitted in partial fulfillment of the requirements for the degree of

MASTER OF FINE ARTS

Portland State Unfversity 1976 
TO THE OFFICE OF GRADUATE STUDIES AND RESEARCH:

The members of the Committee approve the thesis of Anthony Parker presented June 1, 1976.

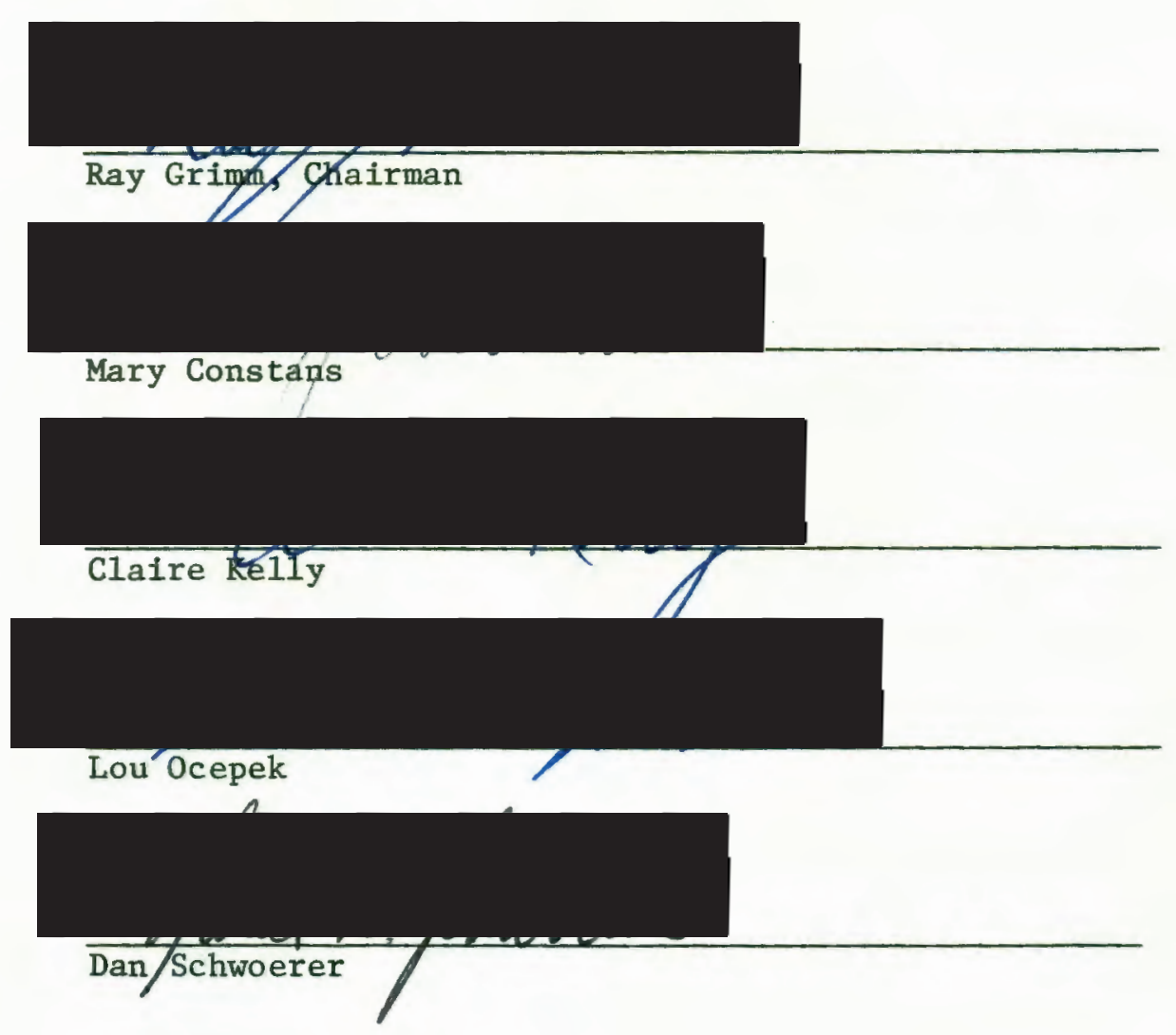

APPROVED :

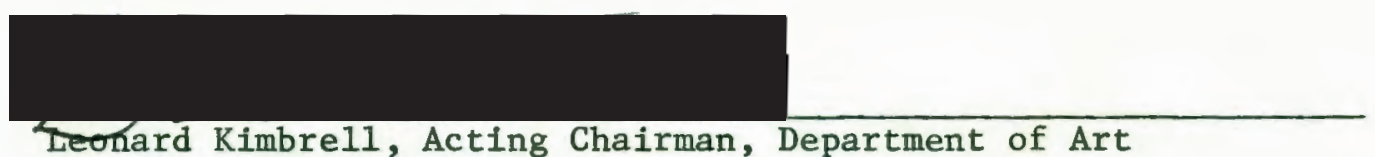

Leonard Kimbrell, Acting Chairman, Department of Art

Richard B. Halley, Acting Dean of Graduate Studies 


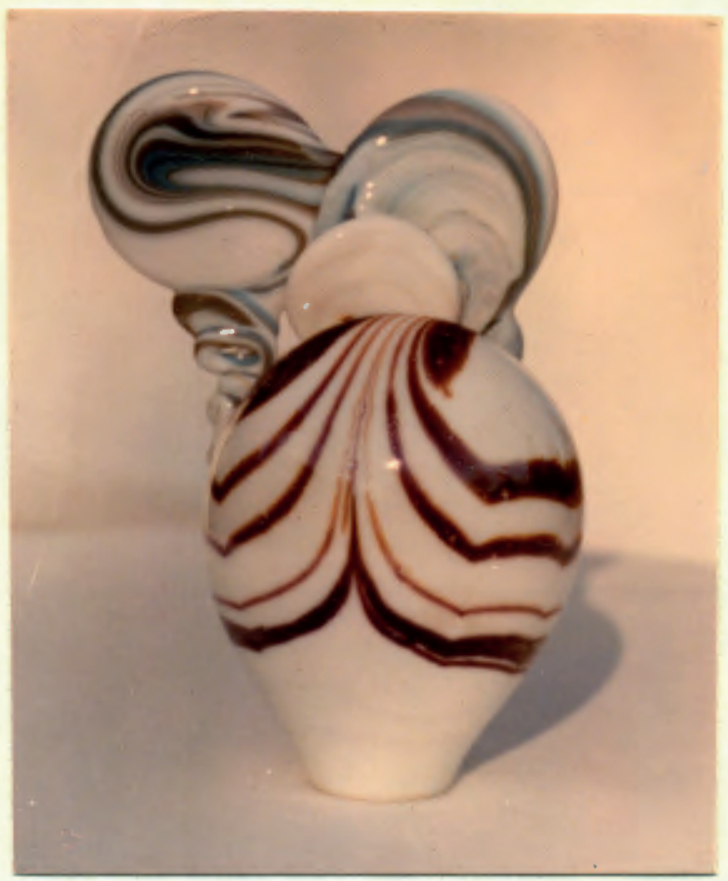

Glass Landscape 
Most glass sculpture suffers from size restraint because of the physical characteristics of glass and the limitations of the glass studio. I have attempted to overcome this rigid dimensional restriction by creating Individual organic glass shapes and by consolidating them Into a group. The piece becomes a life study, landscape, or other natural formation.

I found that carrying out my ideas in glass was less taxing than making the appropriate glass formula itself. My concepts demanded variations in the color, and the ability to transmit 1ight. I built glass furnaces with these special glasses and the techniques of form in mind.

Glass used in this thesis is either recycled opaque cullet purchased from a factory on the east coast of the United States, to which coloring oxides were added, or else is recycled bottle cullet, to which coloring oxides, fluxes, and opactflers were added. The other medium used in this thesis is a light welght concrete body containing grey or white cement, sand, perlite, and some concrete color additives. This cements the Individual glass forms in a base. It is the combination of these two mediums that comprise the major work of my thesis. Some minor pleces are studies of natural form in glass alone.

The colored and opalescent glasses were mixed, melted, and fined (removing the bubbles), pulled from the furnace, and formed. The piece would not crack, if the heat expansion rates of the different glasses were sufficiently close. After a piece was completed, it was cooled gradually for ten hours, and not until after this annealing would it be known if the proceedures were successful. 

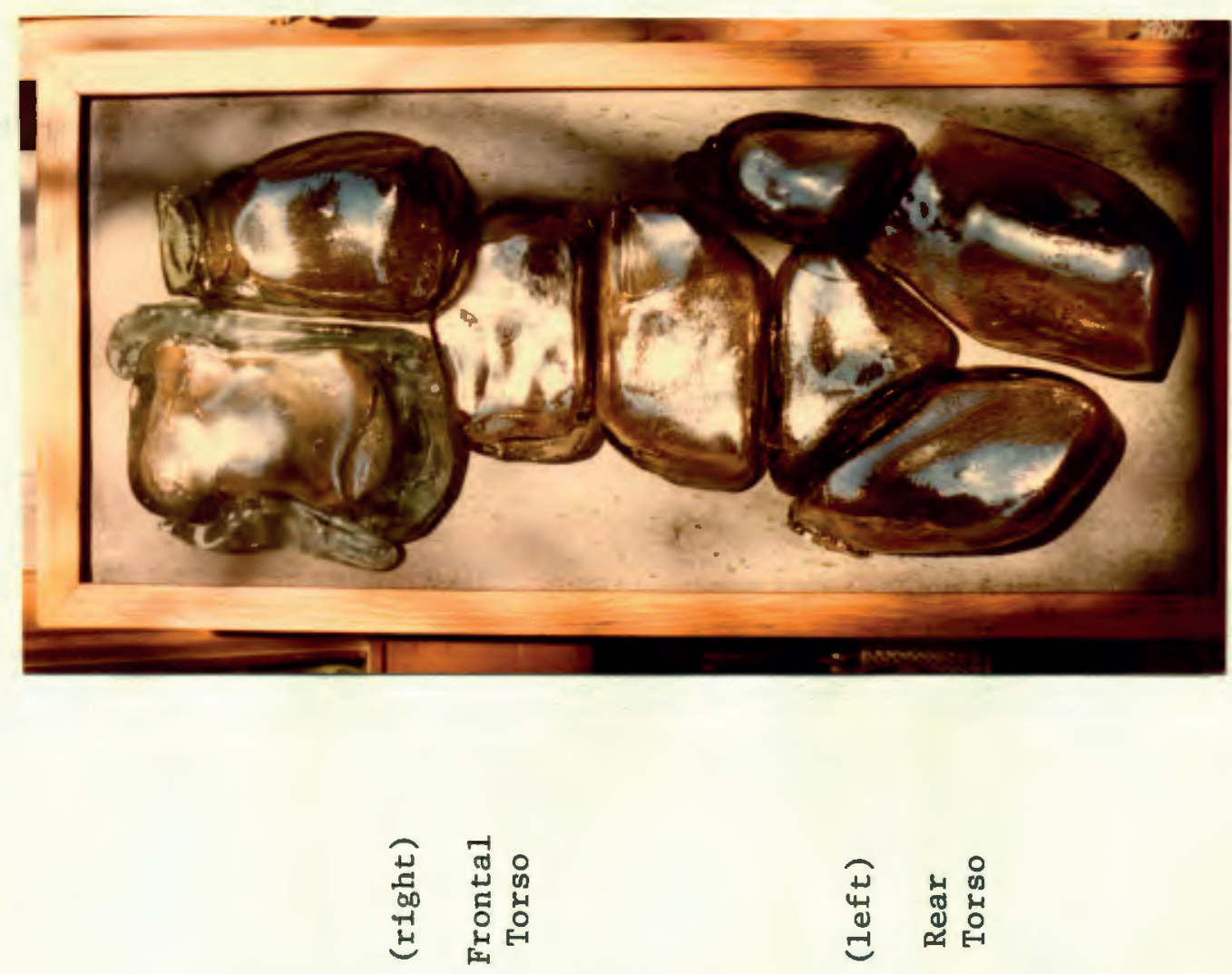

㟧 出

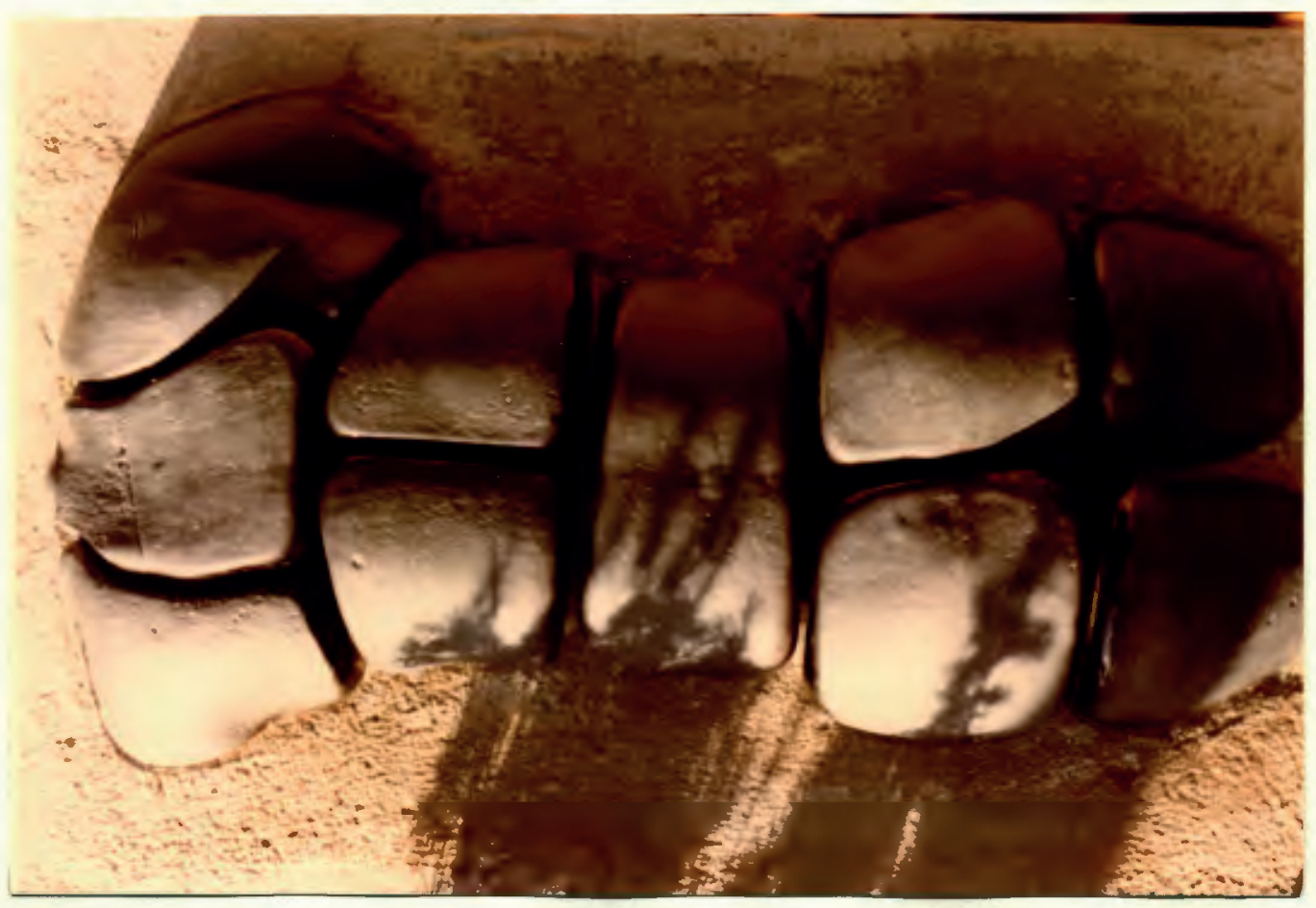


The finished pieces of this thesis are divided into three areas: torsos, 1andscapes, and dalles de verre. (s1abs of glass in concrete as windows).

The torsos are blown pieces of glass that were set in concrete. The original form is a plaster cast of a live mode1. From this negative torso, a plaster positive was poured, and after the plaster set, it was sectioned according to the outlined external features of the torso. From these positive sections a plaster, perlite, and sand mold was cast. These molds were thoroughly dried and heated to $500^{\circ} \mathrm{F}$. Each piece was then blown from the pipe into the mold.

The frontal torso is made of clear glass that has been mirrored. The rear torso is made of black opal glass with an etched surface. The color and surface of the glass are not meant to relate symbolically to the human figure, but rather to play opposite one another as the figures themselves do. While the color, surface, and view are in contrast to each other, the shapes of the torsos are complimentary.

These multiple shapes symbolize the human figure. The intent is for the work to be seen as a recognizable figure by the unconscious movement of the eye. The work of the eye organizes the separate parts. By using multiple glass forms the size 1imitations of glass sculpture is overcome. The pleces combine to form a single, real unit.

After deciding the torso pieces of glass were successful when set In concrete, I experimented with the possibilities of a similar treatment of other natural forms. Looking for that development in a landscape, I began to work with multiples of the natura1 bulb shape in glass. I noticed the simflarities of these shapes to those of the 1andforms in the Columbla River basin area. 
Diminishing Line Perspective

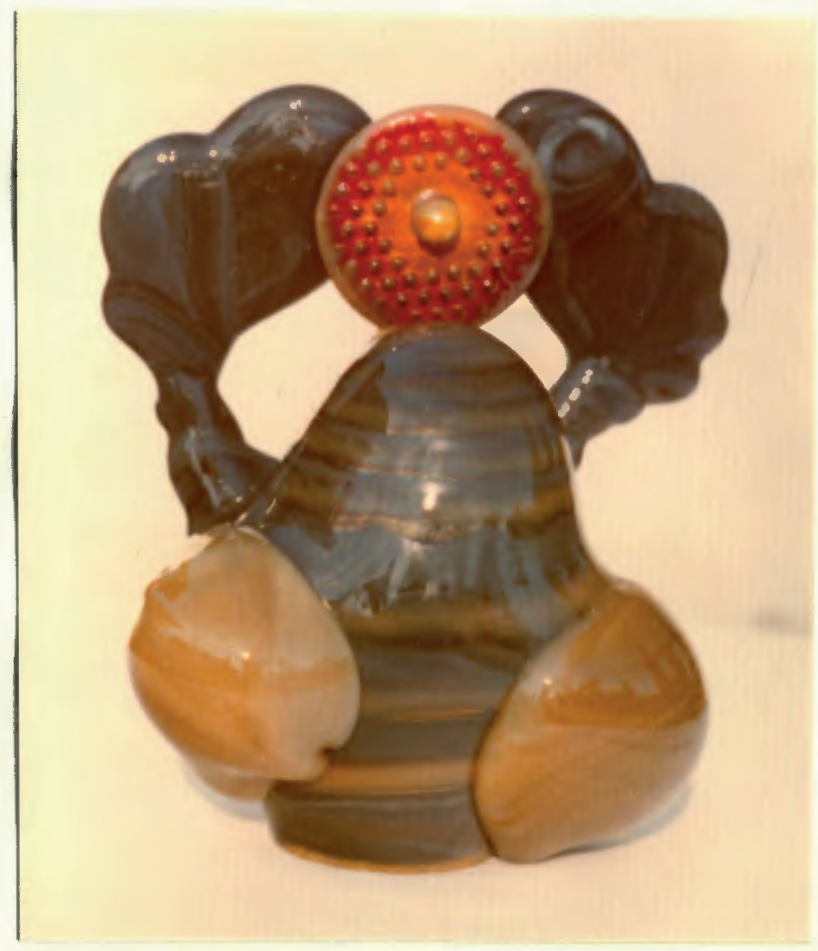

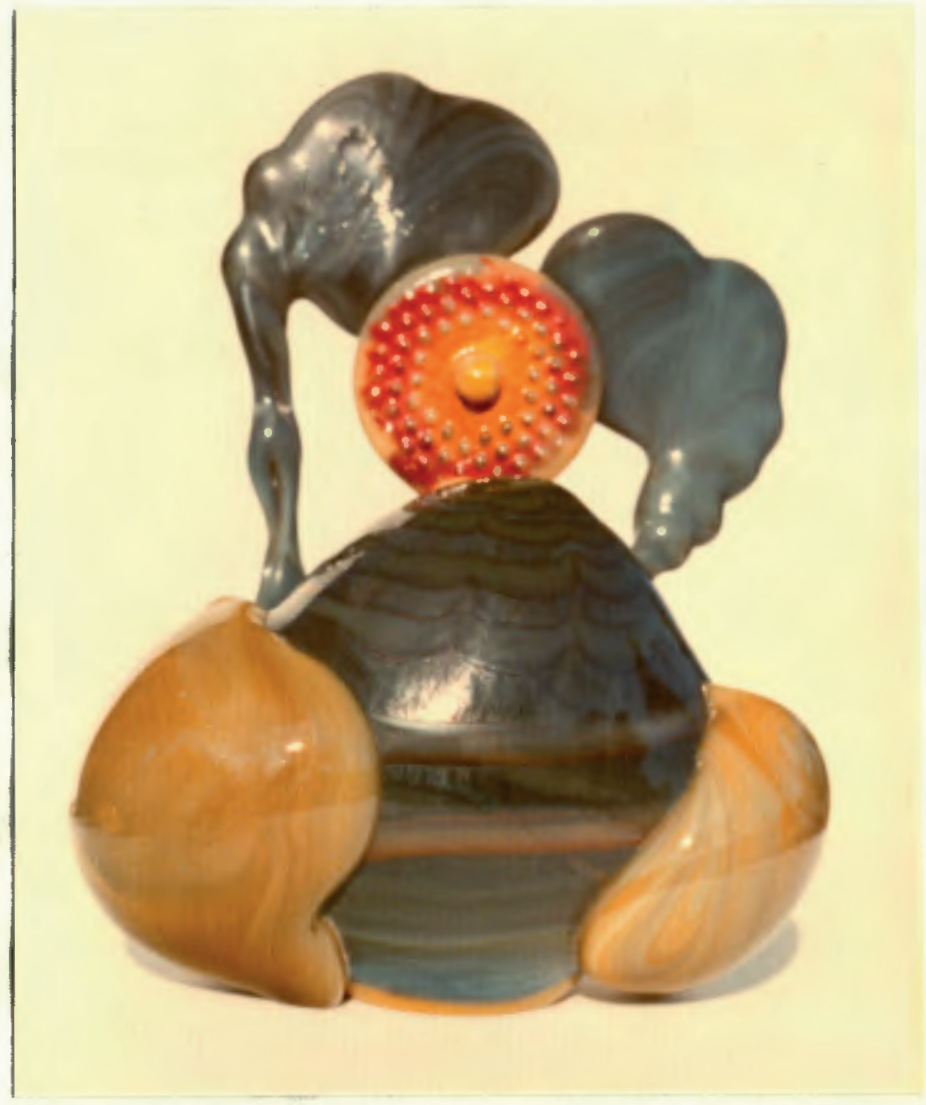


Right: Pulled Line Perspective

Below: Flowing Line Perspective

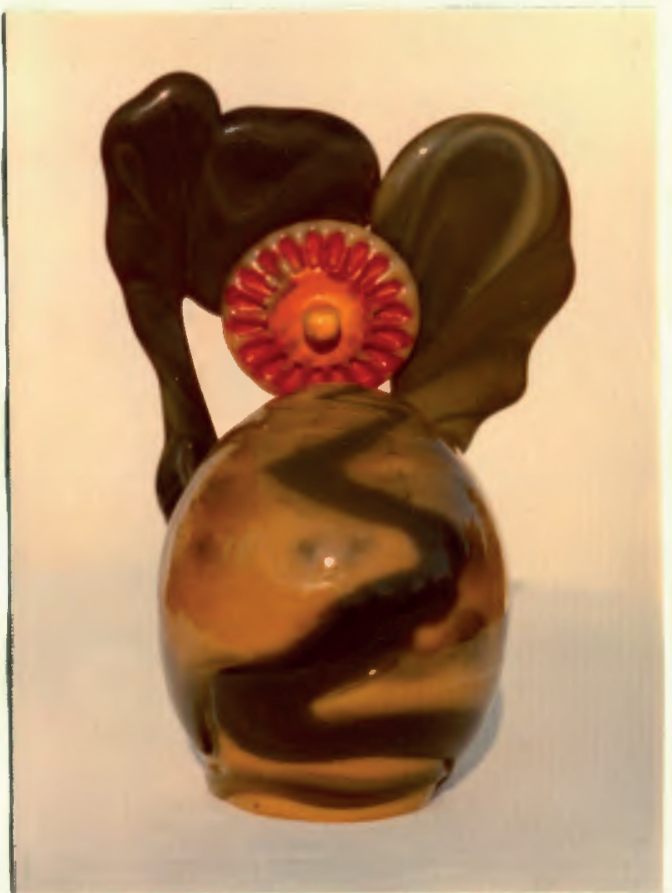

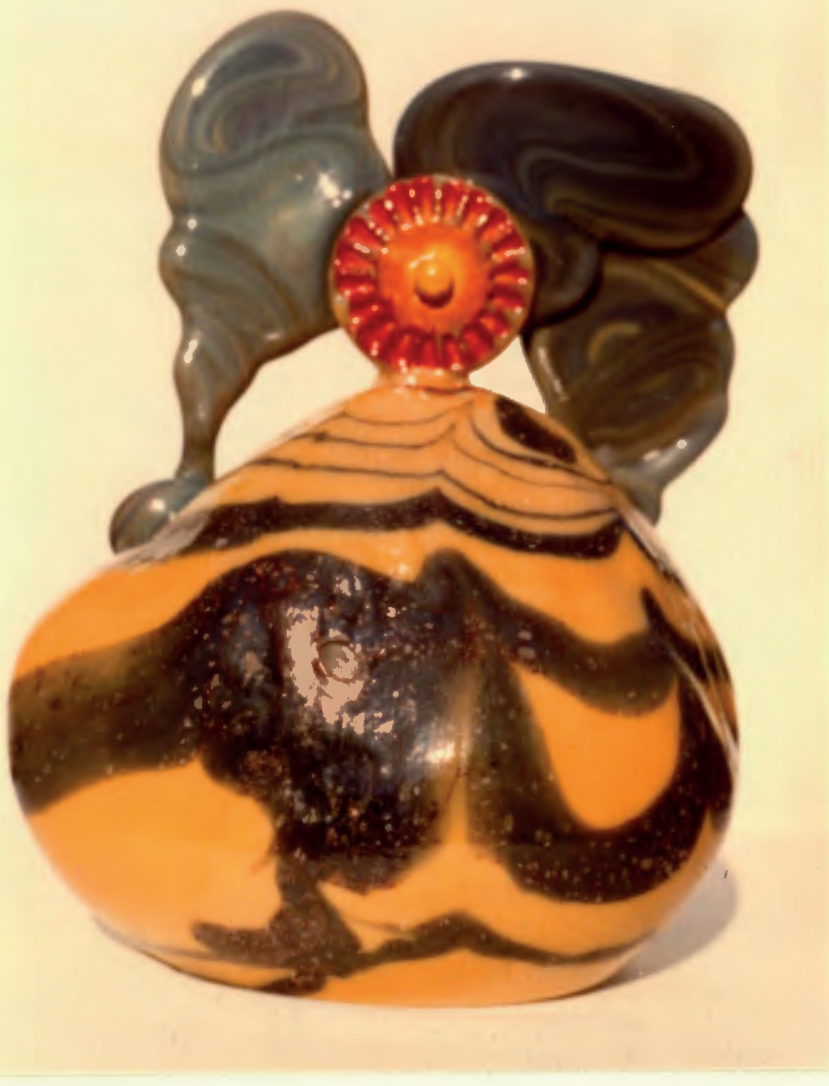




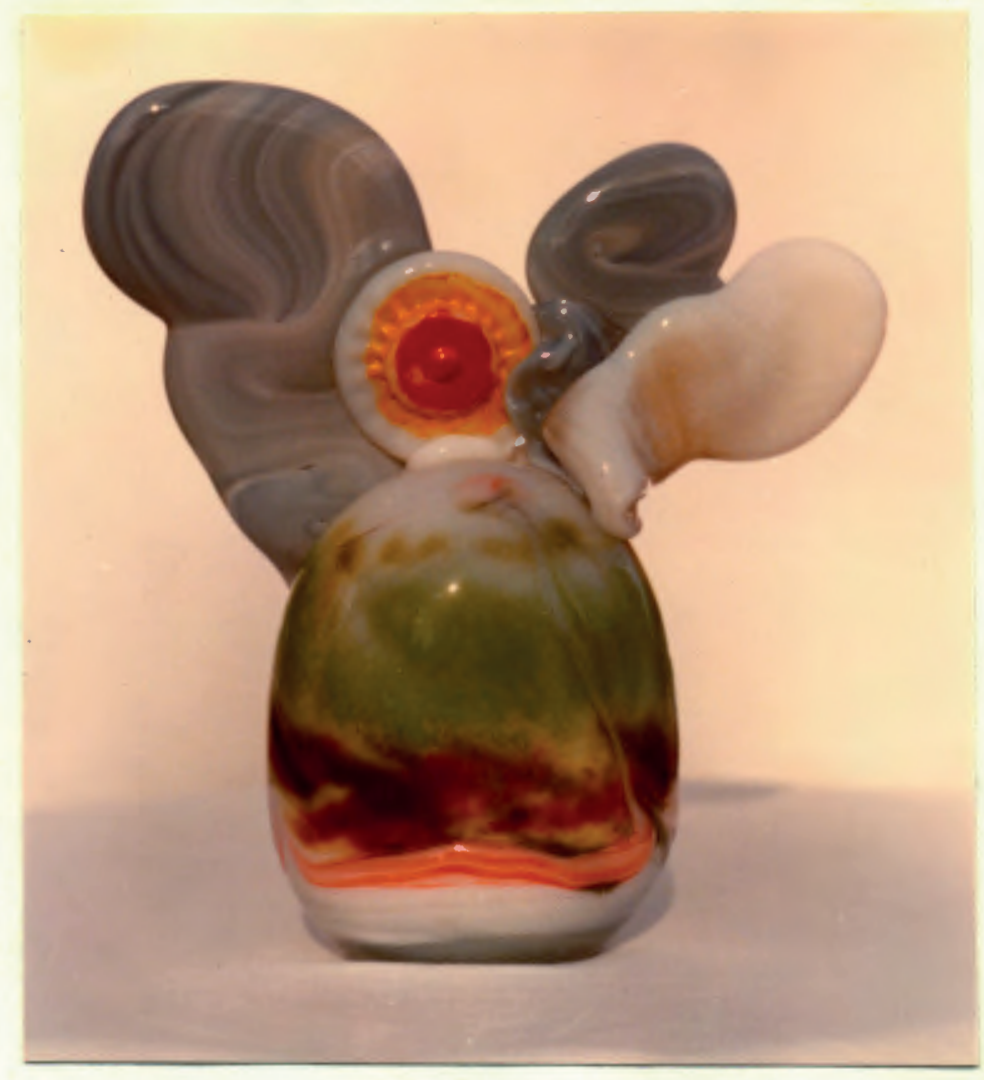

Perspective Through Color Valve 


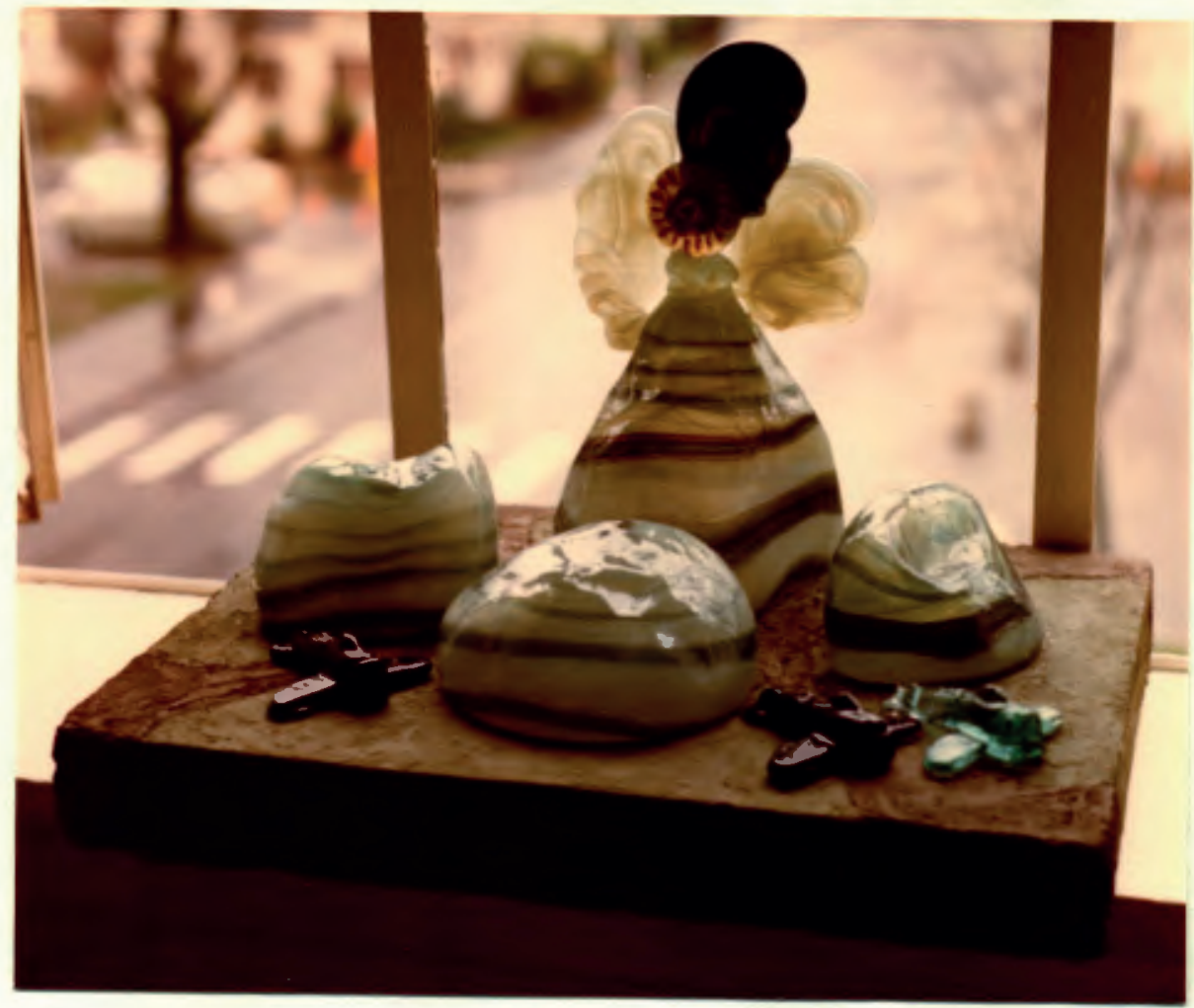

Multiple Landforms in a Concrete Base with Attached Celestial Images

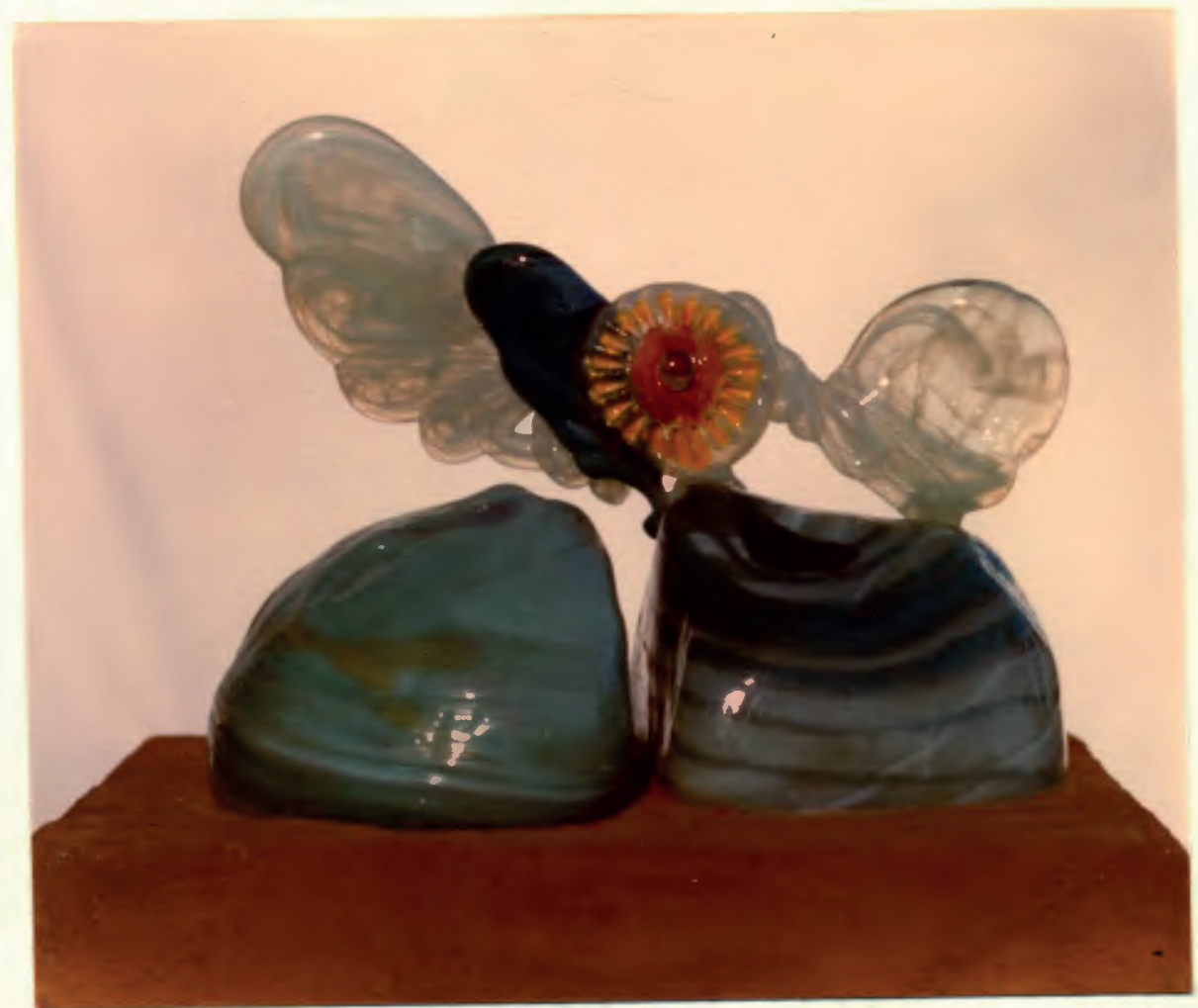


Blown, three dimensional objects became landforms with four twodimensional drawing techniques on the surface of the glass: 1. A diminishing linear perspective makes the form appear to be layered. The lines of color are larger and farther apart at the base of the piece and move closer together and smaller towards the horizon. 2. A pulled line emphasizes the perspective on some of the landforms. The pul1 begins at the base of the plece and moves toward the horizon. 3. A flowing line perspective begins sma11 at the horizon and meanders towards the base. 4. By using a change In color value from the base to the horizon, the work also indicates perspective. Each drawing technique was attempted In each color scheme. The approach to color was a development from the glass. Bright and muted colors were used with gloss and matte surfaces on glass that ranged from clear to opalescent, to opal, with the effort to emphasize the perspective. The bounding and enclosing 11 nes of the additions of cast glass became clouds which with images of natural celestial occurences became landscapes.

As the success of the torsos suggested, I began to cast multiple landforms in a concrete base with cloud images attached to one of the forms. The result was successful in the landforms themselves. The pleces were stable and the multiple forms added considerable depth to the landscape. I was nearly resigned to the $11 \mathrm{mitat}$ ion and the vulnerability of the glass clouds attached to the landforms. However, research in established techniques of joining cast glass pieces revealed a method of making windows with concrete.

Thus, dalles de verre windows are not themselves natural images, but are included because of their value in the development of concrete casting techniques, and because it occured to me that these traditional 


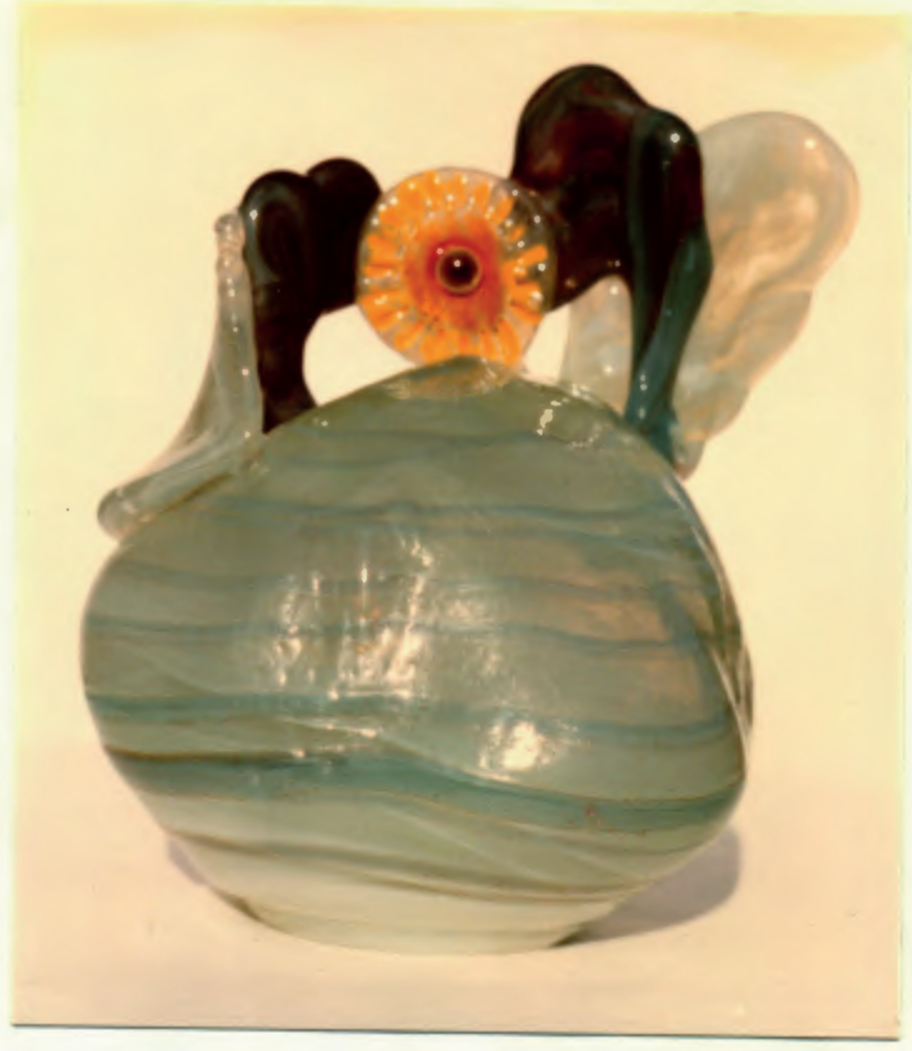

Diminishing Line Perspective

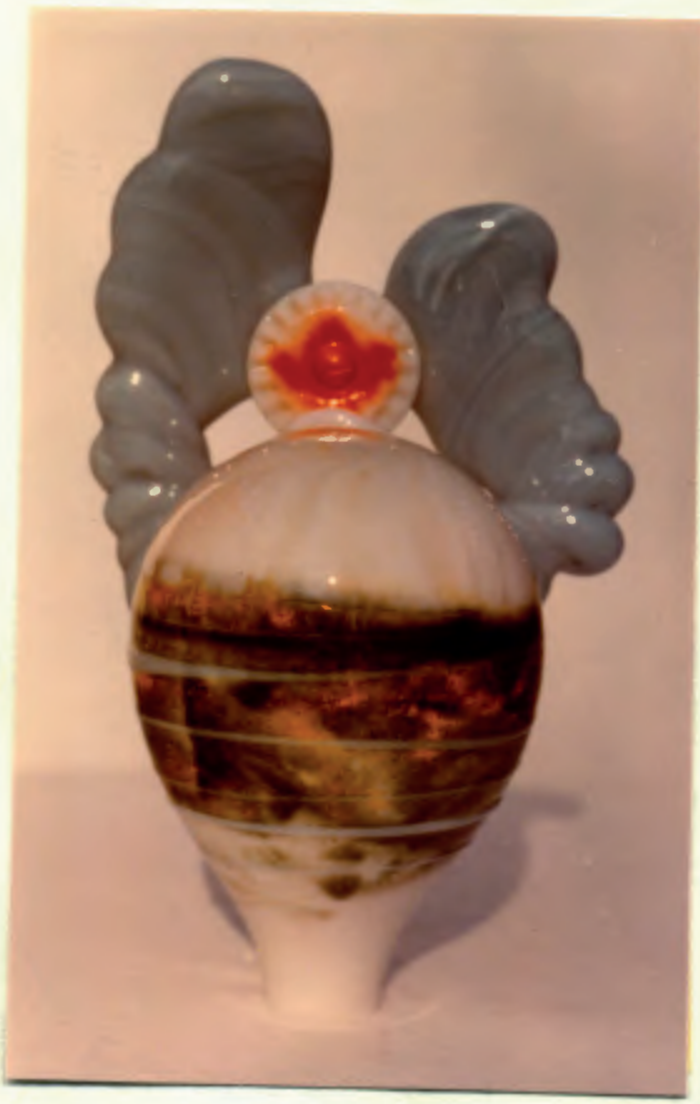


Below: Dimintshing Line Perspective

Right: Pulled Line Perspective
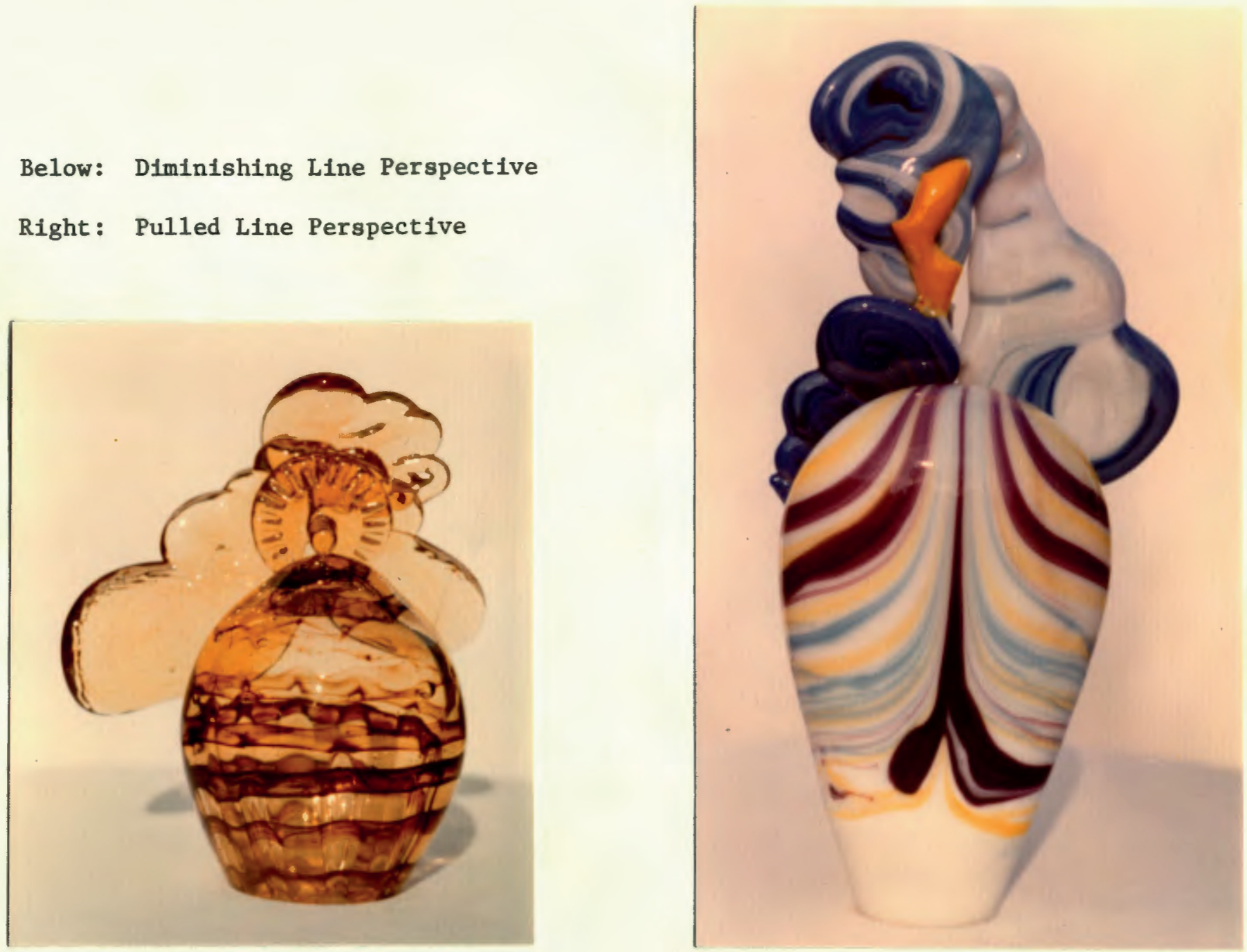
Flowing Line Perspective

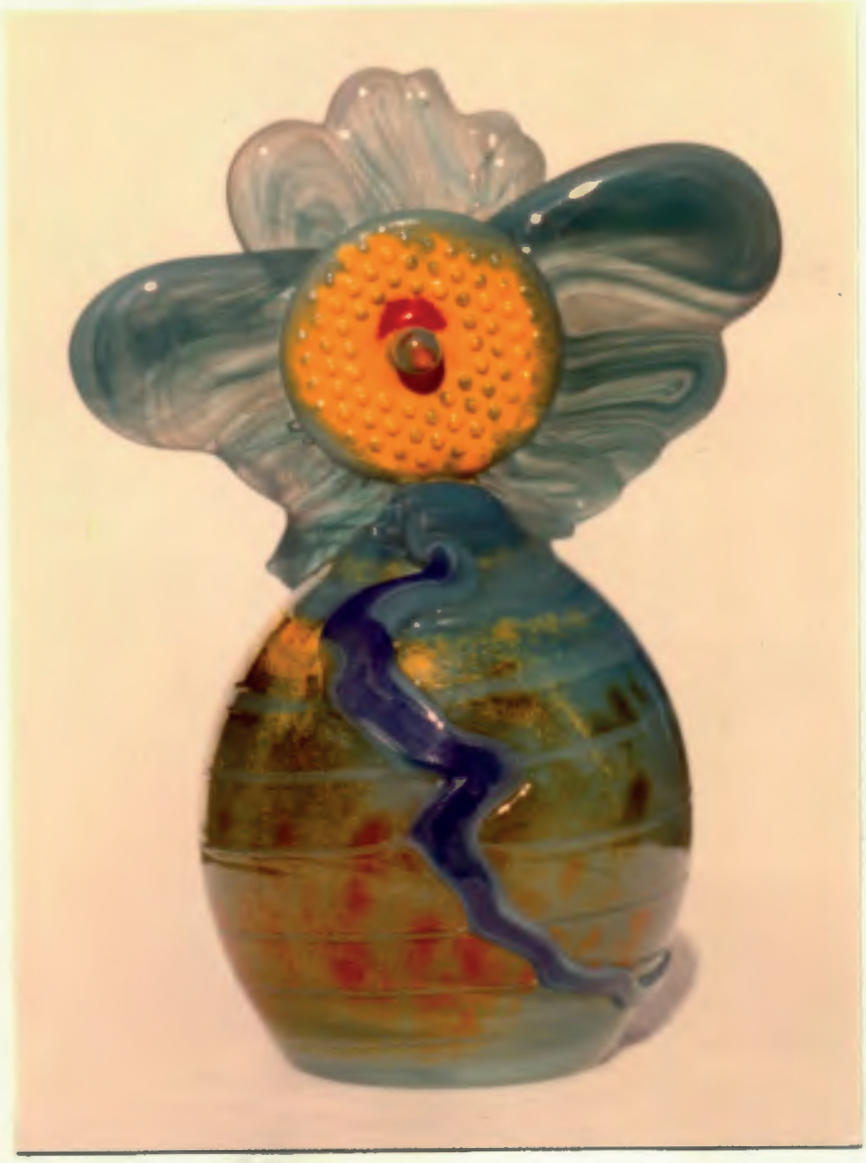

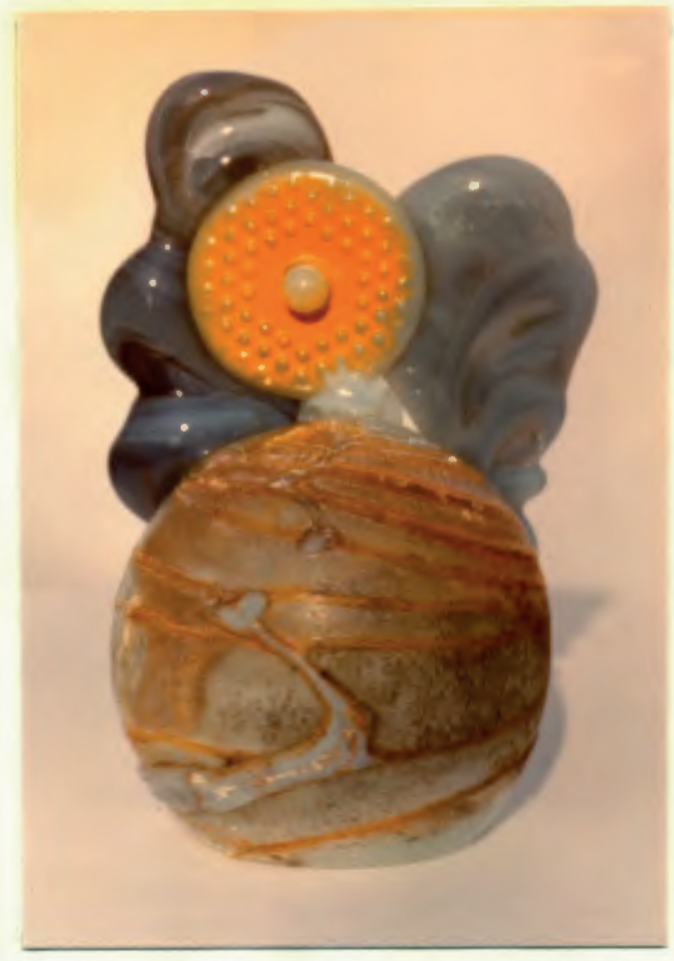

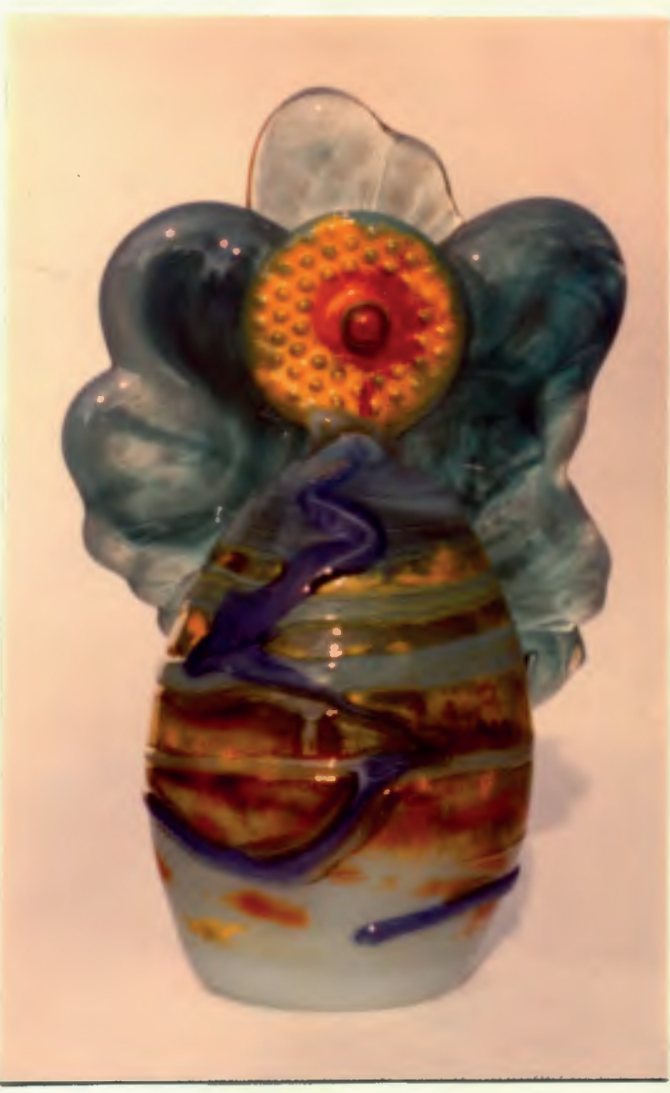


techniques which combine pieces of glass into a large work could be used to overcome size restraint in the natural forms with which I was workIng. The pieces of glass are geometrically congruent. There are natural shapes in the glass and they relate to each other accordingly. The windows are made up of designs in each plece of glass which complement each other when combined into a multiple. Each plece of glass was cast Into a form and pressed with a design while liquid.

After the glass was annealed, a wooden form was made to the outside dimension of the window. A steel reinforcement grid was we1ded into the shape of the outline of the slabs of glass. Each plece of glass was covered with clay to gain the Intended thickness of the concrete. The glass was placed in the steel grid in the wooden form. I had welded nuts to the steel and the steel was suspended by bolts screwed Into the nuts through the wooden form. The same light weight concrete body was then poured over the steel grid and around the glass. After the concrete had set, and the clay had been washed from the glass, the window was removed from the form, and the concrete was chiseled, troweled, and smoothed to finish.

The windows suggested completing landscapes that combined a glass landform In a concrete base with a glass and concrete sky. The sky windows were laid out in the same manner as the dalles de verre, except for and additional solid concrete slab below the sky. After the landform was cast in a concrete base, the sky at the solid concrete slab was mortared to the base.

The finished forms are for the moment frozen into an abstract landscape. Yet, the shape of these forms suggests that perhaps the landscape is st111 moving. Like the land, the glass continues to move 


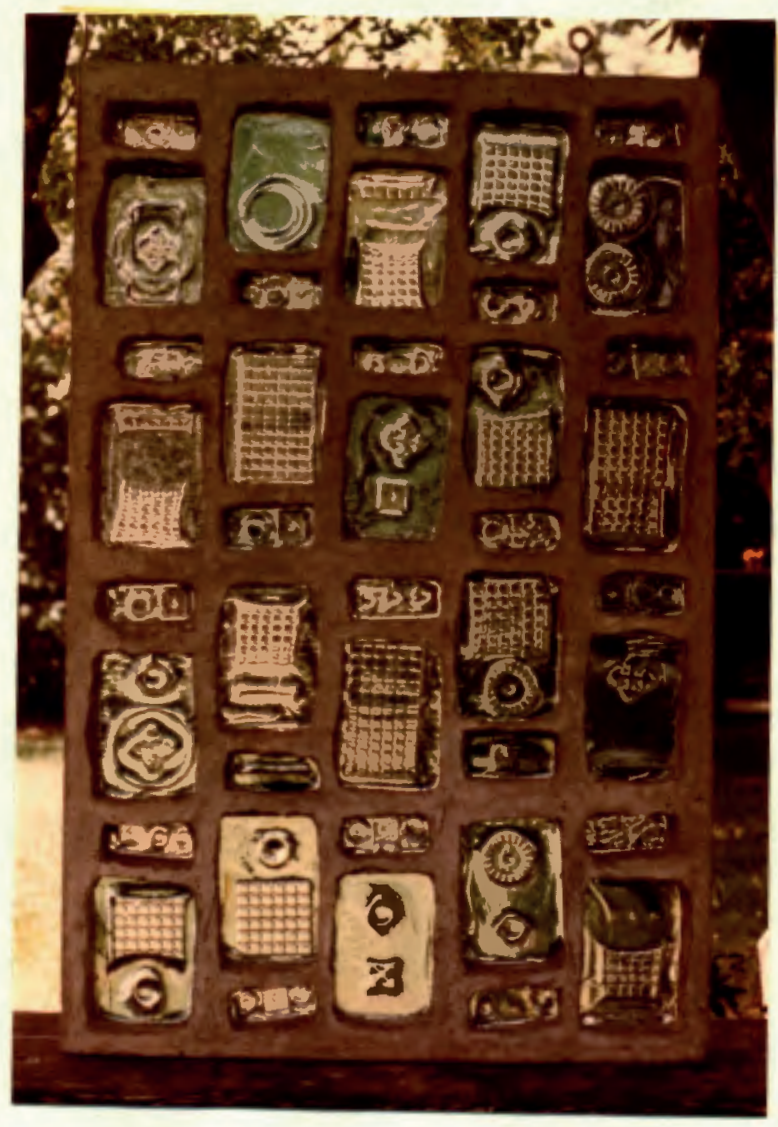

Dalles De Verre 


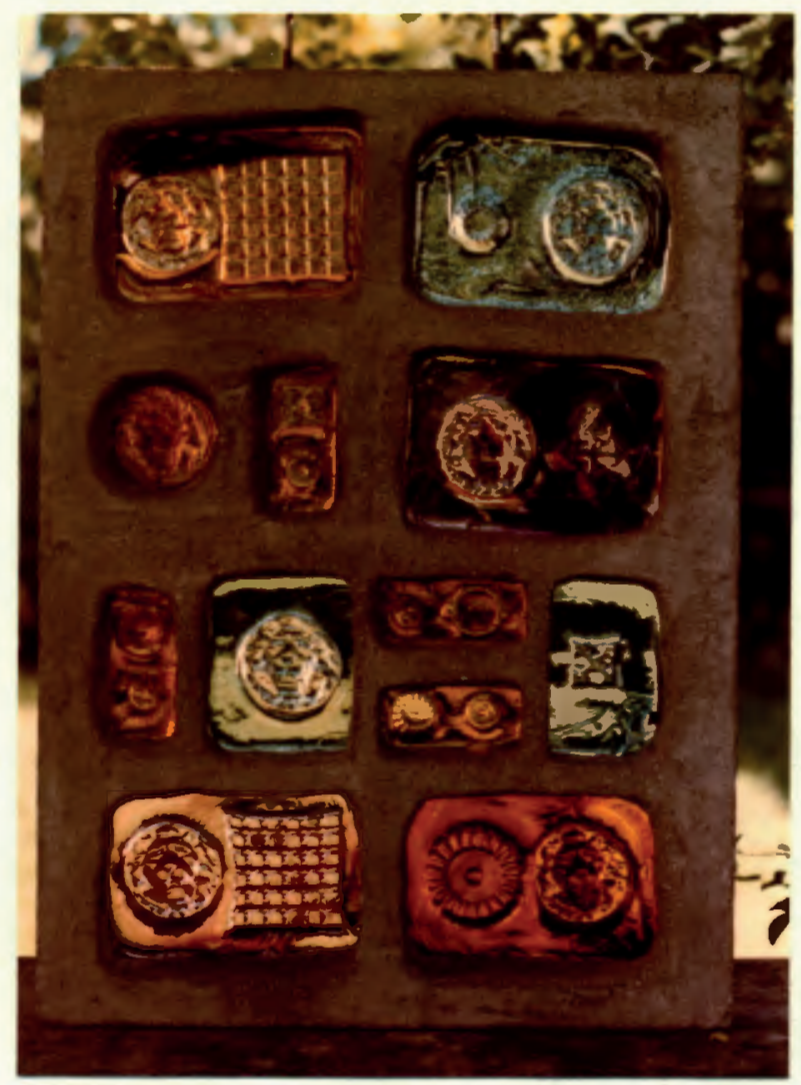

Dalles De Verre 
and after several million years these forms can flow minutely into other shapes. Because glass moves, it lends itself to natural forms. By combining the perceptions of glass as a symbol of landforms, and of a landscape in multiple glass shapes, I expanded the limits of glass sculpture. I think of glass not as a cold, thin solid, but as a hot gooey substance. Hot glass in a furnace moves like molasses, blows like bubble gum on the end of a pipe, pulls 11ke salt water taffy, and sticks 1ike rubber cement. Flowing movement defines glass form, and working with a flowing medium demands spontaneity. Quite often decisions were made as to what should be attempted after the glass was ready to work. During the production the glass changed constant1y and creative decislons depended on the outcome of those changes. 


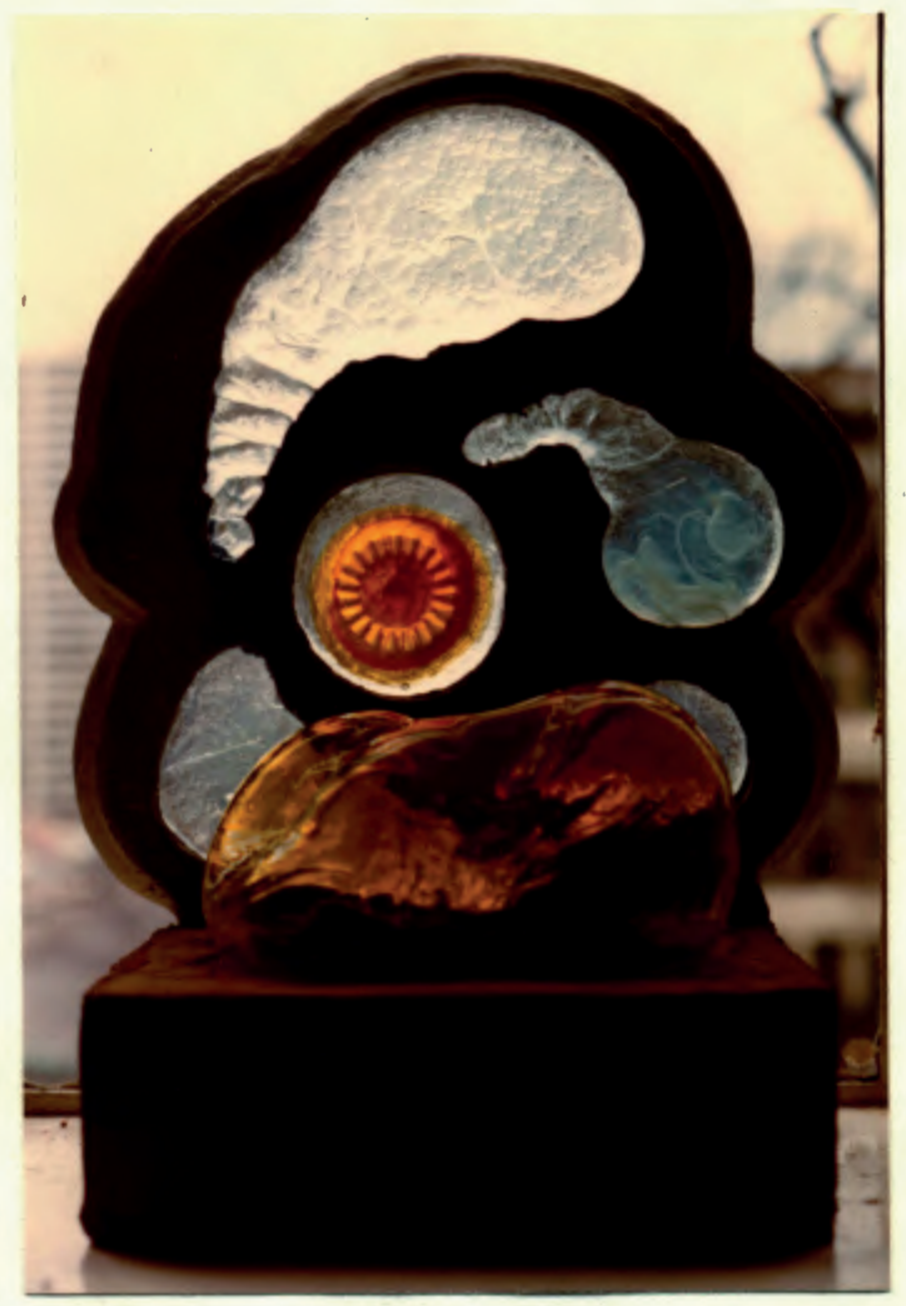

Glass Landform in a Concrete Base with a Glass and Concrete Sky 